Article

\title{
"The First Generation to End Poverty and the Last to Save the Planet?"-Western Individualism, Human Rights and the Value of Nature in the Ethics of Global Sustainable Development
}

\author{
Andreas Spahn (iD \\ Philosophy and Ethics of Technology, Department IE\&IS, Eindhoven University of Technology, \\ 5600 MB Eindhoven, The Netherlands; a.spahn@tue.nl
}

Received: 30 March 2018; Accepted: 26 May 2018; Published: 3 June 2018

\begin{abstract}
The UN Agenda 2030 lends itself to an interpretation in light of the human rights framework and related contractualist ethical theories. These frameworks have been developed in the context of Western individualism. This paper analyses the sustainable development goals in light of the debate between human rights on the one side and the rights of nature on the other side. It argues that human rights are often (though not exclusively) linked to social contract theories. The paper points out strengths and weaknesses of contractualist individualism. It discusses various challenges to the contractualist framework. How can contractualist individualism deal with the representation of future generations? What assumptions does the social contract make with regard to the nature of the individual? Should we conceive of them, e.g., as utility maximizers or as idealized rational agents? A final weakness of the framework is that contractualism seems to ignore other values, especially the value of nature. The paper therefore sketches recent developments in ethical theory that attempt to go beyond Western individualism.
\end{abstract}

Keywords: sustainability; environmental ethics; human rights; social contract; individualism; anthropocentrism; value of nature

\section{Introduction}

Early environmental ethics was faced with a debate about the role of nature and the potential need for a new, radically different ethical framework to deal with the challenges of the ecological crisis [1-3]. It has been argued that traditional ethics in the West focused on the rights of the individuals but failed to develop an elaborated theory of animal rights until the last century [4,5], and that it also failed to give nature a central place in ethical theory $[3,6]$. The argument was that the West has put a high emphasis on the individual and the people-dimension of sustainability but has neglected nature and thus the planet-dimension. For early environmental thinkers, this Western individualism seemed thus to give a mixed picture. On the one side, the protection of the rights of individuals is arguably one of the most remarkable achievements of Western political philosophy. On the other side, the neglect of nature and the danger of individualism turning into egoism is one of the greatest challenges underlying the ecological crisis. The main worry of early environmental ethics was therefore that our ethical systems in the West were mostly anthropocentric. We put a high value on humans but we do not have a solid ethical theory about the value of nature. Nature seems to only play a role insofar as we humans need a healthy environment in order to survive.

The move from millennium goals to sustainable development goals in the UN Agenda 2030 seems to point towards a stronger emphasis on sustainability, and one of the dimensions of sustainability is environmental sustainability. Can we interpret this as further move from 'people' to 'planet'? 
In this essay, I place my engagement with the 2030 Agenda in the context of the debate between Western individualism on the one side and the call to include nature more systematically in environmental ethics on the other side [7]. The call to include nature has both been argued for in the debate on intercultural philosophy around energy justice $[8,9]$ and within the Western tradition of early environmental ethics [1,3]. A closer look at the UN 2030 Agenda reveals that the human rights framework is mentioned prominently at multiple passages in the text, whereas references to values of nature are rare. This need not be a bad thing, since the human rights framework is indeed a powerful ethical framework, which is well embedded in Western traditional ethical theories. What, then, are the benefits and limits of placing the debate about sustainable developmental goals in the context of the human rights framework?

To answer this question, I will analyze the human rights framework and its link to social contract theory and Western individualism. I will refer to an interpretation of the human rights framework in the light of social contract theories as "contractualist individualism". With this, I refer to a family of political philosophies that (a) takes the rights and needs of the individual as the primary or even only moral value within ethical theories; and that (b) interprets moral duties within political philosophy and society as being explained and justified by some form of a social contract. Contractualism in philosophy is thus the idea to justify our political norms by subjecting them to the question of whether rational agents would have reason to jointly agree upon these norms. Contractualism can either refer to real factual agreement of individuals or to hypothetical consent.

I will argue that contractualist individualism has its main strength as a theoretical framework when it comes to justifying people-related sustainable developmental goals, including the protection of nature insofar as this is instrumental for the well-being of (future) human beings. However, there are three main challenges. First, we need to acknowledge the short-comings of contractualism as a procedural theory. This becomes particularly relevant, as I will try to show, in the case of sustainable developmental goals. Second, the underlying assumption of 'rational egoism' of the individuals in contractual situations poses a challenge for intergenerational dilemmas. Finally, I will argue that philosophy should move beyond individualism and include the value of nature, and thus go beyond Western individualism.

\section{Human Rights and Social Contract: The Case of Sustainable Development}

It goes without saying that the UN 2030 Agenda for Sustainable Development as such is neutral with regard to specific ethical, philosophical or religious worldviews in order to allow a plurality of countries and individuals to identify with the goals, rather than suggesting any specific ethical framework that could give a normative justification of these goals as binding. The goals in itself are of course often linked to values, but these values are mostly very general, uncontroversial values, as you would expect from such a policy document. Next to people, planet, prosperity, peace and participation, fundamental values such as human well-being, health, justice, equality, living in harmony with nature etc. are mentioned [10].

There is, however, one striking exemption with regard to the framework-neutrality of the 2030 Agenda: the human rights framework is explicitly acknowledged as a shared principle and commitment and referenced at various occasions in the text [10] (pp. 4, 6, 9, 29, 32). Again, this is not surprising, given the historic importance of the UN Declaration of Human Rights of 1948 and its prominence as a legal frame of reference for the activities of the United Nations. Philosophically speaking, the starting point of human rights is, however, not as neutral as it may seem and seems to pre-structure the discourse on sustainable developmental goals as belonging to and standing in the tradition of Western individualism and rights-based ethical approaches. The rights and needs of the individual take center stage in sustainable developmental goals. This need not be a bad thing, as it goes without saying that the protection of individuals, especially the weakest members of society, is an important aim and the human rights framework starts from the idea of protecting the basic rights of all individuals; but does starting from this framework not imply the danger of a neglect of the 
rights of nature and animals? What are the pros and cons then of approaching the issue of sustainable development through the perspective of human rights?

The philosophical foundations of the human rights framework can historically be linked back to the rising acknowledgement of the unconditional value of all human beings, encompassing the idea of a principal equality of all humans. In the West, ideas of universalism and equality have been developed in the Greek philosophy and been supported by secular and non-secular traditions of universalism, culminating in the political and ethical theories of the Age of Enlightenment [11,12]. The idea of equality and universal rights of all individuals therefore has many historical roots, but it took a long time to emerge as a key paradigm of political philosophy. Henry Maine analyses the transition in Ancient Law [13] from a status-oriented society to an ever-growing emphasis on equal rights. According to Maine, the role and legal status of a person was determined in traditional societies by the place he or she occupied in that society. In the modern interpretation of political philosophy, however, the relation between individual and society is turned upside down according to the new individualistic framework. It is no longer the society that should determine your rights, but the other way around: a society as such should be organized according to the principle equality of all its members. "From status to contract" is the legal shift that Maine identifies as a paradigmatic transition towards modernity. With Thomas Hobbes, John Locke and Jean-Jacques Rousseau, we see the emergence of social contract theories that interpret the state as a contract between otherwise free and equal individuals, who leave the 'state of nature' by transferring part of their powers to the state [14]. The state in turn has the function to protect the freedom and the rights of the individuals who constitute the state [15].

Thus, we can see how the two ideas of human rights and the social contract are connected. If we assume that all human beings have fundamental rights, then it follows that others have duties to respect these rights. The duty to respect the rights of others constitutes both a claim towards society and social institutions as well as a claim towards fellow human beings [16]. If we take the rights of individuals as a starting point, it is plausible to interpret the society along the line of social contract theory: free and autonomous agents will want to live in a society that guarantees basic rights and freedom. I would like to refer to this position as 'contractualist individualism'. A contractualist individualist interpretation of society takes the plurality of equal and autonomous human beings as a starting point and interprets political obligations and ideals, such as the sustainable developmental goals, as the result of a real or counterfactual social contract. The idea of human rights guarantees the moral status of these individuals, and the higher sphere of society needs to be interpreted in light of these rights (social contract theory can thus be seen as a version of a more general ontological 'individualism' "in which everything, indeed every possible object, is either an individual or a collection of individuals" [17]. Western individualism would thus be a political version of atomism in physics. For an overview and critique of different dimensions of individualism, see [17]).

There are different approaches within philosophy on how to justify human rights within ethical theory. I cannot enter into the debate about which of the suggested theories is most promising [18-20]. Standard accounts encompass most prominent ethical theories. Intuitionists will argue that human rights are based in self-evident intuitions about the moral status of individuals. A utilitarian conception will justify human rights in light of basic interests of human beings, whereas accounts in the deontological tradition will take moral agency as a starting point and claim that, as moral agents, humans have a right of protection of their capacity to act (morally) [21]. Finally, contractualists will attempt to justify the human rights framework as the result of an ideal social contract itself: human rights are then understood as the basic principles of morality that all rational human agents will agree upon under ideal circumstances. The dichotomy between interest-based or deontological conceptions might reappear here: we can imagine the individuals that agree to the social contract as either focusing primarily on their interest (e.g., imagine them as utility-maximizers), or as perfect moral agents that give consent out of a sense of duty (i.e., imagine them as idealized Kantians).

In the following sections, I will primarily focus on the contractualist interpretation and leave it open for now how we conceive the individual agents that should give their consent to the social contract. 
The contractualist interpretation of the human rights framework faces an often-discussed dilemma: there is a gap between real agents agreeing on any topic in a given, concrete situational context and the ideal counterfactual agents that give their consent in a hypothetical situation, e.g., behind a veil of ignorance [22]. I will argue that a human-rights based framework of the sustainable developmental goals must pay attention to this gap. This implies, as we will see, a number of philosophically relevant consequences. I will attempt to show that the rational agent paradigm that follows the utilitarian interpretation of utility maximization has serious shortcomings once we turn our attention to the topic of sustainability. For sustainable developmental goals, a deontological framework seems more promising. The gap between real and ideal contracts also urges us to restructure our societal institutions such that they compensate for the inbuilt bias towards currently living people. Furthermore, I will argue that the utility-maximizer paradigm is, as we learn from psychology, not plausible anyway if we want to understand the behavior and actions of real humans. While all of these criticisms could be accounted for by a deontological interpretation of human rights, there is one remaining shortcoming: the inbuilt anthropocentrism in both contractualist individualism and deontology points to the unsolved question of the value of nature.

\subsection{Human Rights and the Social Contract: The Strength of the Framework}

This brings us to some of the main strength of the human rights framework. I would like to mention three main advantages of connecting the sustainable developmental goals with the framework of human rights.

The first is that, in its contractualist interpretation, the rights-based framework mirrors the self-understanding of the United Nation as a platform in which individual member states jointly agree upon policy principles. It was already the vision of Kant in his book on perpetual peace to apply the idea of a social contract not only to the relations between individuals within one society but to the community of states as well. In the same way in which the social contract brought peace and stability to the members within a society, an effort to create supra-national structures between existing states would bring about a more peaceful world, as Kant hoped [23]. This vision can be interpreted both as a material ethics and as a procedural ethics. Materially, Kant aims to identify the values and principles that are needed and binding for all nations to live in peace. The human rights framework can be seen as such a material basis of fundamental rights, based on material values such as human well-being and/or human dignity. The social contract dimension adds the idea of a procedural ethics: the political process should be guided by the idea of a contract of equal partners, jointly agreeing upon the principles they want to live by. The Völkerbund and the United Nations, imperfect as they were/are, attempt to take this program into practice.

If one looks at the United Nations from the individualist contractualist framework, the idea of a cooperation in the spirit of fostering the well-being of all individuals emerges. Nations no longer compete in the spirit of self-interest, but establish a civilized forum for dialogue, in which they act according to joint ethical principles such as the ones that are mentioned at the beginning of the 2030 Agenda. Therefore, calls to further strengthen participation and mutual learning are thus repeated throughout the 2030 Agenda, together with the call for a multi-stakeholder partnership for sustainable development $[10,24-26]$. Thus, we see how the procedural element and the material element of social contract theory is present in the 2030 Agenda: it calls for "responsive, inclusive, participatory and representative decision-making at all levels" [10]. Finally, after criticism of the process leading to the Millenium Goals, the UN undertook a serious attempt to make the process of arriving at the 2030 goals more transparent and participatory and stresses the element of participation [27]. We can thus argue that contractualist individualism is in line with the self-understanding of the UN as expressed in the text.

Secondly, the human rights framework can serve as a plausible interpretation and foundation of most of the 17 goals that are mentioned in the 2030 Agenda. This seems to be true both for the interest-based and for the will-based conceptions of human rights. In the interest-based, utilitarian 
version, the goals aim at fostering the well-being of humans (e.g., ensure healthy living and promote wellbeing; make cities inclusive, safe, resilient and sustainable;) or at diminishing or eliminating pain or harm (e.g., ending poverty; ending hunger; combatting the impacts of climate change) [28]. In a deontological interpretation, the different goals are rooted in the respect for human dignity as a moral agent. In the Kantian framework, human dignity is linked to the capacity of being a (moral) agent [29]. The necessary conditions to exercise agency are thus of fundamental importance, as is the promotion of freedom. For many goals, it is clear that they can be interpreted in that way; e.g., the alleviating of poverty and hunger, and access to quality education contribute to the free exercise of autonomy and moral agency. The Kantian interpretation also seems promising for those goals that focus on justice and/or the fundamental conditions of equality (e.g., achieving gender equality; reducing inequality within and among countries; provide access to justice for all).

The goals that focus on the role of nature are more difficult to interpret in the light of individualist contractualism. One could try to postulate a human right to a healthy environment, as John Knox the UN special rapporteur on Human Rights and the Environment has recently suggested, and thus link sustainability to the idea of health [30]. Furthermore, the rights of future generation can be used to justify efforts to protect the planet and the eco-system [28,31-33]. I will come back to this question later; let me only mention here already that most of the passages in the text that call for the protection of nature can indeed be read as being either implicitly or explicitly motivated by anthropocentric concerns.

The third and final advantage of the human rights framework is that it is an established framework within international policy and has broad support within the community of political philosophy and ethics. Despite all of its weaknesses, it is thus wise to build on this existing framework before trying to implement new and more far-reaching frameworks. It is fair to say that non-anthropocentric values are hardly implemented currently in national, let alone international, frameworks. Linking sustainable development to the human rights framework thus gives it a solid anchoring in broadly accepted international principles [28,31,34,35].

\subsection{Criticism of Western Individualism and the Role of not-yet-Existing Individuals}

Despite these arguments in favor of linking the sustainable developmental goals to the human rights framework, there are also some challenges. I will discuss the concern that the framework is Western-centric and cannot easily be applied to other cultures (Section 2.2.1); and the difference between social contract theory regarding currently living individuals (Section 2.2.2) vs. future human beings (Section 2.2.3). Finally, I will challenge the underlying assumption about what constitutes rational individual behavior within social contract theories (Section 2.2.4).

\subsubsection{Contractualism and Human Rights as 'Western' Frameworks}

The first challenges is that the human rights framework, especially in its contractual-individualist interpretation, might be perceived as a 'Western framework' [36]. The worry is that the supposed universalism does not render justice to the plurality of values that we find in different cultures, and that it 'accidently' chooses a concept that was mainly developed in the West as a guiding principle and thus neglects alternative principles for a multicultural policy agenda. The worry might also be that it imposes a Western individualist lifestyle on other cultures that might not be in line with more communitarian or collectivist ideas (for a critique of the individualism-collectivism dichotomy see [37].) [38]. It has been argued that, e.g., Asian cultures value the well-being of the community higher than the individual and tend thus to put priority on the social dimensions of human rights over more individualistic aspects of human rights. One dimension in which cultural traditions might thus differ regards the polarity of individualism and collectivism [39]. Similarly, Islamic countries have established the Cairo Declaration on Human Rights in Islam, which provides an Islamic (non-secularist) perspective on the human rights framework [40]. 
However, even though it is true that any intercultural universalistic ethics will have to combine valid ideas from different cultures, one could argue that the universality of respecting human dignity is an ideal that should not be given up. In fact, the idea of human dignity is not a Western invention, even though the human rights might have first been elaborated in the West [29]. Along this line, it has indeed quite early on been argued that ideas of "freedom, human dignity, tolerance and neighborliness" can be found in many different cultures and are not just 'Western' concepts [19]. The human rights framework should further be seen as guaranteeing a minimal set of fundamental rights to basic necessities for agency without determining richer notions of moral self-understanding. Human rights should thus be seen as a morality of the depth, as Henry Shue has called it [41], that can be complemented with more concrete culturally different values. Human rights should therefore be seen as offering a minimal consensus to protect basic needs of all humans, that is compatible with more advanced ethical self-understandings.

Finally, one could argue that there are more obvious points of departure for criticism of Western mentality than aiming at the human rights framework. In the next section, I will focus on the justified criticism, in my eyes, of modern individualism. Here, I just want to mention several points of departure for a criticism of recent Western philosophy. Rather than targeting human rights, one could attack, e.g., the tendency to measure well-being primarily in terms of economic growth, thereby ignoring more substantial notions of happiness [42]; the loss of community-identification and traditional virtues of caring in modern industrialized societies that has been criticized ever since Rousseau and Marx $[15,43,44]$; and finally, the tendency to see nature first and foremost as a resource that we can use and exploit as we like [45]. I will get back to this criticism in Section 3.

\subsubsection{Social Contract and Current Individuals}

Before we get to these critics, I want to point to a more fundamental shortcoming. This concerns the procedural element of social contract theory. The main point I want to stress is that the gap between real social agreement and counterfactual ideal agreement is even bigger in the case of sustainability. As I have argued above, contractualist theories often assume idealized situations of decision making: all agents are rational, well-informed, and are not biased by power or other interests. Since these conditions do not exist in reality, the demand of contractual individualism on society is to shape real decision-making processes such that they are more likely to lead to the same results as an ideal agreement of free rational agents. To use a metaphor: the task is to arrange the societal atomism such that the force-field of interaction favors the common good and rules out distortions by power-imbalance and strategic egoism [46]. Understood like this, politics is about getting the rules and institutions right such that existing individuals can jointly agree on (and contribute to) the common good.

The challenge for this approach is, however, that future generations in principle can not participate in this arrangement: their force is absent in the game of coordinating individual interests. Let us look at this point in more detail. The aim is not to look at all the intricacies of reality and real interactions, but to understand the structure of contractual individualism and why its procedural ethics must fail in light of sustainability and future generations.

Under a social contract theory of human rights, the moral community and similarly the real society is conceived as consisting of a plurality of free rational individuals that strive to jointly agree upon societal matters. This process of deliberation must then follow strict rules in order to guarantee an unbiased justified outcome. In line with this interpretation of society as a realm of contractualist individualism, we can then (ideally speaking) develop solutions to distribution-problems, such as the distribution of power and the distribution of market goods. The assumption of contractual individualism is that free choices of individuals under strict rules of fairness are beneficial for society and guarantee just outcomes.

The (neo-)liberal theory of the market, which follows Adam Smith, is the text-book example for this line of thinking. Given certain constraints, the market is supposed to guarantee fair prices and should lead to an effective distribution of goods and money, which in turn fosters the "wealth 
of nations" and thus benefits all individuals [47]. The difficulties and limits of this approach are well-known. The theory optimistically assumes overly idealized markets and ignores challenges such as asymmetry of information, monopoly-formation and other imperfections of the markets. For the context of this paper, I merely want to stress the contractualist individualist logic behind this idea. It is a central insight of Adam Smith-who after all also was a moral philosopher-that egoism on the level of individual behavior can lead to societal benefits if (and only if) the egoism of individuals is coordinated and if this coordination is regulated properly. Smith was relieved to have discovered a theoretical framework that combines egoism on the individual level with increase of wealth and well-being on the societal level, since-as he rightly noticed-altruism is often in short supply, whereas egoism is not. In traditional political philosophy, such as the model of the state in Plato or Aristotle, individual virtues were seen as the pre-condition for the success of the societies, whereas in modernity these two can part ways: individual vices, such as egoism, might contribute to societal goods [15].

The regulation of the markets is, however, of crucial importance for this model to work. A free reign of egoism without any coordination would be detrimental to society, as Smith is well aware. If, e.g., also court-rulings are subjected to the logic of the markets and it is possible to bribe judges, the system loses its benefits and the resulting market transactions can no longer be called 'fair'. In short: according to the logic of contractual individualism, the market should rely on free and voluntary transactions of individuals that follow an inner logic that is watched over by the state. The logic of the market thus pre-supposes in this model the sphere of politics.

For the sphere of politics, we can easily see how contractualist individualism applies the same model again: the best way of guaranteeing politically fair results is to foster free exchange of arguments and viewpoints of the individuals. The state is not conceived "top down", but with "we the people" as the starting point (an anonymous reviewer pointed out that there could be cases in which it might be morally more desirable to have successful, stable "top down" governments, even if they are not straight-forward democracies. This might be preferable if such regimes lead to economic growth and overcome dramatic poverty crises, as opposed to very unstable democracies in which parts of the population suffer dramatically. I agree that the principles of democracy and alleviation of poverty and/or suffering might come into conflict. I cannot discuss this here; see, for a detailed analysis of these difficult, often tragic moral conflicts in international politics, [15]). Contractualist individualism thus favors democracy and processes of deliberation and participation. Again, these processes must, however, be regulated such that only the better argument counts and that external forces (such as power and money) do not bias the outcome [46]. The calls for participation and strengthening networks of participation in the Agenda 2030 are in line with this idea, as I have argued above.

Contractualist individualism can then add a final layer. If we regard states as 'individuals', we see how contractual individualism again would call for international cooperation of free and autonomous states that jointly strive to solve international conflicts and seek cooperation and peace. It is here that the idea of a United Nation has its philosophical foundation in the contractualist individualism framework. (As mentioned above, two interpretations are possible as the extremes. If one sees the foundational element in the power of rational agreement, one will always attempt to interpret real compromises in the light of a counterfactual deliberation of an ideal community of communication. If, on the other extreme, one mainly regards contractualist individualism as being situational, then the real interest of the individuals becomes powerful and one arrives at a Trumpian interpretation of the United Nations as an arena for transactional international politics, where not joint ideals, but mainly joint (and opposed) interests matter. One clearly sees the advantages of the idealist interpretation of social contract in the light of this worrisome return to "us first" politics).

\subsubsection{Social Contract and Future Generations}

In light of sustainable development goals, it has become evident that this model has reached its limits. Even though future generations will be humans, and as such have basic human rights [48,49], they can in principle not participate in these real contractual relations. There is no way that they can 
enter the negotiation game directly. They have no purchasing power: their needs and demands are thus not reflected in the market prices. Similarly, future generations cannot vote. Their voices are thus not automatically represented in voting and in the deliberation processes [6]. Politics must thus compensate for this shortcoming, either by forcing the market to price in these externalities (e.g., by climate taxation) or by implementing ways to more systematically represent the non-represented in societal deliberation. For the later one could consider, e.g., a council on future rights as a chamber of the parliament that has a veto-right in case proposed laws threaten the basic rights of future generations [49,50] (an anonymous reviewer rightly pointed out that there is even an under-representation of the future in current voters: in many ageing Western societies, the youth are underrepresented, since young voters form a minority. One could consider, e.g., the case of the Brexit, where the majority of young voters wanted to stay within the EU, whereas the older generation voted mostly in favor of Brexit. It will, however, arguably be mainly the young generation that will have to live with the long-term consequences of this decision).

Basing political philosophy on contractualist individualism of moral agents thus makes sense only if these agents share a joint reality and have to agree on a set of rules in their joint world. This is where the strength of this model comes in; this is where calls for participation and deliberation are of relevance. Multi-stakeholder deliberation can be meaningful, even if it is not always guided by the principle of consensus, but might have to follow the compromise model more often than the consensus model in question of sustainability [51]. However, all these procedural interpretations of contractual individualism aim at changing the 'real' world. However, whatever changes we make, we can per definition not let future generations take part in present distribution or deliberation processes.

This is why environmental ethicists who want to use contractualist frameworks should stress the importance of counterfactual thought-experiments about idealized consensus. These thought-experiments are needed to establish the preferences that individuals should have (as opposed to those random interests they happen to have due to their actual place in current society). These thought experiments, as in Rawls' veil of ignorance [22], can then serve as a guiding principle to overcome particularity and group biases. In the German version of contractualism, Apel and Habermas distinguish in this spirit the real from the ideal community of communication [46,52].

\subsubsection{Are Individuals Utility-Maximizers? Ideal and Real Individuals in Social Contract Theory}

How should we thus conceptualize these "idealized agents" if we want to make contractualism fruitful for the discourse about sustainable developmental goals? It is here that we begin to see more clearly, in light of recent debates, that these ideal agents can and should not be conceived as rational utility maximizers. Why is that?

To start with: one of the limits of contractualist theories is that individuals are supposed to enter into a joint contract because the outcome is beneficial for all parties. Thomas Hobbes has thus argued that rational egoists will agree to form a state because giving up power to a central authority is better than living in a permanent state of civil war of everybody against everybody. However, it has early on been argued that Hobbes' contractualism cannot explain why contracts should be kept once they are no longer beneficial for any given individual [15]. It seems that contractualism only works if we assume some general moral principles to begin with, such as the principles that one has a prima facie moral obligation to keep contracts.

To get a deeper understanding of this, we can furthermore look into more recent insights from game theory and its relation to social contract theory [15,53]. Game theory convincingly shows that, in many cases of social interaction, the greater social good and the Nash-equilibrium of maximizing rational utility fall apart. Especially in dealing with commons and dealing with future generations, we often face a prisoner dilemma situation. For the rational egoist, it is not clear why he should sacrifice anything for future generations, as he gets nothing in return [54,55]. Gardiner has argued that it is individually rational for current generations to pollute, even though it is collectively rational for society to protect the planet (if by rational we mean maximizing utility). Whereas the hope of traditional individualism is that a coordination of joint egoism will lead to the socially desired outcome, 
the environmental crisis is another example that shows that a coordination of egoism cannot be the final solution, especially not in prisoner dilemma situations [55].

What is worse is that traditional solutions to the prisoner dilemma situation that might work in other cases do not work in the case of future generations. We know that reciprocity and repeated interaction diminish the chance of prisoner dilemma situations to occur: rational individuals have more incentives to cooperate and take the interest of the other into account if they expect either a win-win-situation to arise or if there is a chance of meeting the other person again in the future [56]. These traditional solutions, however, do not work in the case of climate change: we have no repeated interaction with future generations, and they cannot reciprocate: what has the future ever done for us?

To conclude, it should be clear that there is an urgent need to overcome the bias towards currently living individuals in the case of sustainable development. The needs and rights of future generations must be made more salient. We also see here a danger of the rational agent paradigm. We have become so used to seeing the benefits of letting enlightened egoism reign in freedom in our market places (as long as the market is intact) and of letting enlightened egoism reign at the voting booth (as long as the basic rules of policy and decency are in play) that we have difficulties understanding ethical theories that go beyond mutual coordination of self-interest. In traditional economics, game-theory and in some branches of psychology a 'rational agent' is simply identified as someone who maximizes his or her own gain—alternative behaviors, such as altruistic behavior, appear then as irrational [57]. This use of the word 'rational' as just meaning 'egoistic' should worry philosophers and environmental ethicists. There is a long philosophical tradition of interpreting reason either as including ethical wisdom or-in the case of Kant-as demanding moral behavior.

Luckily, we see that the rational egoist paradigm is not a plausible depiction of human behavior. Psychological research seems to indeed suggest that real humans are not the utility maximizers that game theory and traditional economics assumed they were. In studies on prisoner dilemmas, participants over and over tend to act less 'rationally' than expected. Rather, they cooperate more often than would be in their individual self-interest [58,59]. Similarly, it has been shown that people want to act in line with their values. Framing sustainable consumption choices as saving money (and thus appealing to self-interest) often work less effectively than making the value 'care for the environment' prominent in a choice situation [60,61]. Also, there is ample evidence that people do care for the environment [62]. The rational agent paradigm might have caused more damage in the West than needed, as it forces us to assume that people that care for other things than themselves are somewhat less rational.

To conclude, contractualist individualism has its limits. The first one is that it cannot easily implement future generations in the 'real' deliberation processes. The question of sustainable development for future generation is not a coordination problem of diverging interests. We need to recognize that we have to structurally change participation and deliberation processes to give a voice to the non-represented. Secondly, the starting point from rational utility maximization might not be a good starting point for a theory of human rights. The model of rational egoists who jointly agree under the veil of ignorance about the best solution, might not be the best theory to frame ethics, when what is asked from us is often to go beyond our immediate self-interest.

A way forward could be to go beyond contractualism and take a deontological stance in the interpretation of the framework. Human rights are not constituted by agreement of ideal agents, rather they are non-negotiable. Even a community of ideal agents behind a veil of ignorance is bound by the respect for human dignity [29]. However, such a theory of human dignity would still be anthropocentric. Can one not raise a more fundamental objection: the debate about sustainable development goals should move beyond the human rights framework, because the framework is anthropocentric and ignores the rights of animals, and the rights of nature?

If this critique on contractualist individualism is plausible, then there are indeed different ways forward, as an anonymous reviewer rightly pointed out. One could investigate alternative stances within the realm of individualistic ethics (such as e.g., virtue ethics or capability approaches) to give a 
broader foundation to the sustainable developmental goals. One could consider earlier approaches of the Western tradition or emphasize the role of the "community" over the rights of the individuals. I want to suggest that the most interesting way forward in the context of sustainability is to consider non-anthropocentric ethical theories. It might precisely be an acknowledgment of the value of nature that could compensate some of the shortcomings of Western individualism.

\section{From People to Planet: Beyond Anthropocentrism?}

As has been argued in the introduction, the Agenda 2030 calls for sustainability along the various dimensions of people, planet, prosperity, peace and partnership. In particular, the agenda recognizes the urgent need to improve the situations of humans, while at the same time emphasizing the need to live in harmony with nature. In its probably most noteworthy formulation, the Agenda describes the enormous tasks ahead by saying: "We can be the first generation to succeed in ending poverty; just as we may be the last to have a chance of saving the planet" [10] (p. 12).

Whereas in the first half of the sentence the $\mathrm{p}$ for people is most prominent, the second half points at the planet dimension of sustainability. The hope to end the problem of hunger and to preserve nature might remind philosophical readers of the line of argumentation in early environmental ethics: a shift from a human-centered ethics to a more encompassing ethics, which acknowledges the rights of nature. Climate change seems to call for a re-consideration of the value of nature.

It is clear that the human rights framework and contractual individualism are anthropocentric approaches. This obviously, however, does not rule out a concern for nature. In an anthropocentric framework, there is also a moral duty to preserve nature. However, within anthropocentrism, the reason to care for nature is that the well-being of future humans depends on nature. Nature as such does not have any intrinsic value for anthropocentric ethicists. As mentioned before, in the 2030 Agenda, direct appeals to the rights of animals or the rights of nature are rare, as opposed to the focus on human needs and human rights. Should we be worried about this fact from the perspective of environmental ethics?

I will not be able to solve the difficult questions of non-anthropocentric ethics in this essay. Being rooted in a Kantian framework myself, I nevertheless recognize some of the short-comings of the absence of nature in ethical theories. There is rising criticism that a plausible notion of sustainable development must go beyond anthropocentrism. This criticism mirrors a concern in the comparative intercultural philosophy discourse. In intercultural philosophy, it is argued that the West focuses too much on individualism and neglects both the value of the community and the ideal of living in harmony with nature. Contractualist individualism takes the agreement of rational agents as the starting point of ethics: nature has no fundamental place in this picture. The strength and limits of such a model of political philosophy that focuses on the individual have been discussed above. Also, within the West, contractualist individualism is the result of century-long cultural development and must therefore be put into a historical perspective [15,63]. It might indeed be about time to follow the call to include non-Western perspectives more systematically in the quest for giving a philosophical foundation to the sustainable development agenda.

We see early attempts of this happening. For example, Benjamin Sovacool and others have recently addressed criticism in the energy justice scholarship that their earlier work on philosophical foundations in the sustainable developmental goal debate mainly takes its inspirations from traditional and current Western perspectives. A first attempt was made to include non-Western perspectives. Also here, the focus on community and nature are key ideas that seem more vibrant in other cultures $[9,64,65]$. I would support the claim that Western approaches to energy ethics need to be extended in these two dimensions to be a more comprehensive framework for a truly global sustainable development [8]. Certainly, there is work to be done here for philosophers, and it is not an easy challenge to bring together intercultural ethics and environmental ethics. In what follows, I can only present initial ideas with regard to important domains, in which a human rights framework and its inbuilt individualism need extension. 
It seems implausible to me, however, to structure this debate as an either-or choice. As I have argued above, contractual individualism is a powerful framework when we talk about both the rights of individuals and the role of social institutions in guaranteeing these rights and pushing for just societies. There is no need to abandon the human rights framework; on the contrary, respecting human rights is still an urgent task and must be part of every meaningful notion of sustainable development. However, there might be reason to complement the human rights perspective with additional values. This might be particularly urgent if we focus on developed nations that score relatively well with regard to the protection of human rights but poorly when it comes to environmental sustainability. Specifically in the West, the task of politics might now not primarily be to protect the free and autonomous individuals from the collective, but to protect the collective from all the free and autonomous choices of the utility-maximizing egos that lead to the privatization of gains and the externalization of costs to the community and future generations [15].

This complimentary perspective can come from philosophical traditions of other cultures in the spirit of mutual learning and participation. In the remainder of the article, I would, however, like to point to important developments within Western philosophy that could be used in the quest to develop a different perspective on nature, and thus to philosophically support the 'planet' dimension of the sustainable developmental framework. We find in different recent philosophical traditions important elements for a reconsideration of the value of nature. I will point to examples from phenomenology, critical theory and analytic philosophy. I will argue that we find early attempts to move beyond individualism in each of these positions, and that these ideas need to be further elaborated in future debates about the ethical framework for sustainable development.

Husserl already criticized the scientific worldview as an incomplete abstraction that does not render justice to the richness of the phenomenological experience of the individual ego [66]. Heidegger has elaborated this critique in his influential essay 'The Question Concerning Technology' [45]. The main thrust of the argument is directed against the modern understanding of nature in relation to modern technology. He rejects the idea that technology is a neutral instrument to reach one's end (what he calls the "instrumental definition of technology"), and he also rejects the idea that technology should mainly be understood as a human activity in which humans develop and choose technologies that serve their needs (the "anthropological definition" of technology). His view is rather that modern technology is embedded in a very specific worldview: a worldview that regards nature just as a mere resource, which we can exploit. From the perspective of modern science, nature is just a mere object, stripped of all values and relations to human interactions, that is free to be manipulated as we see fit. At the core of the problem thus lies an incorrect conception of nature.

According to Heidegger, this worldview is both one-sided and dangerous. It is one-sided because it ignores alternative approaches to nature and regards them as less valid. The way in which nature can serve as inspiration, as a source of admiration or retreat, both in everyday life and in art is being neglected and has no place in this instrumental philosophy of technology. This worldview is further dangerous as it invites an instrumental view of the world in which we first exploit and dominate nature, only to then go on to dominate and exploit other humans. In his essay, Heidegger himself is mainly concerned with the diagnosis of this mindset, but he does not himself develop a solution. He vaguely points at art on the one side and the connection between art and technology in Greek antiquity without elaborating this alternative in any sufficient detail.

(Whereas Heidegger's critique on technological instrumentalism is very convincing, his negative view of science tends to ignore more pure motives of science. Science also allows for pure contemplation about the laws of nature, without an immediate interest in technological application of this knowledge. Generally speaking, we often find in Heidegger a skepticism towards modernity that allows him to see the pathologies of modern science and technology very sharply. The same skepticism, however, often leads him to underestimate the beneficial developments of modernity. Post-phenomenology has therefore tried to go beyond Heidegger and acknowledge the positive aspects of modern science and technology, without ignoring the ethical worries). 
Heidegger's pupil Hans Jonas elaborated both a detailed ethics for the technological age, along with a detailed philosophy of nature [3,67]. His main argument in his ethical work is that the relation between nature and humans has dramatically changed due to modern technology. Whereas in the past humans had to protect themselves against the forces of nature, in our day and age, we need to protect nature against the forces of human civilization and its pollution. Jonas thinks that this is only possible if we develop a theory of values in general and the value of nature in particular. His philosophy of nature is meant to provide the missing alternative interpretation of nature, that could overcome the scientism that Heidegger criticizes. Hans Jonas starts from Heidegger's analysis of human existence and gives it a foundation in our biological nature. According to Jonas, the organic lifeform brings "value" into the world. Organisms are vulnerable creatures that "care" for their existence. Therefore, the environment becomes meaningful for them. Jonas analyses the interdependencies of humans and nature and argues for an ethics of responsibility, in which humans strive to live in harmony with nature. Unfortunately, Jonas is often neglected in debates about sustainable development. His work could serve as a starting point for a re-evaluation of the value of nature and give a philosophical non-anthropocentric foundation to those sustainable developmental goals, that concern the protection of the environment $[68,69]$.

We can see the emergence of similar ideas also in other traditions outside of phenomenology. Critical theory has developed, from a different philosophical starting point, a strikingly similar critique on Western instrumentalism and its picture of nature. Habermas identifies the will to dominate nature as an underlying motive for the rise of modern technology and science, that serves strategic rationality [70]. In modernization in the West, scientific knowledge becomes the role-model of all knowledge; other types of knowledge that are important sources of human values in our lifeworld are seen as mere subjective beliefs. Habermas thus tries to re-establish ethical knowledge in his elaborated works on discourse ethics and the theory of communicative action [71]. However, critical theory in Habermas does not go beyond the scientific worldview when it comes to the value of nature: Habermas has no elaborated philosophy of nature. His ethics keeps the traditional starting point of the social contract theory of the interaction of rational agents.

We finally also find in analytic environmental ethics a debate on the question of the intrinsic value of nature that mirrors the concerns by Heidegger and Jonas but uses a different argumentative strategy. The last person argument is used to show that nature has an intrinsic value that goes beyond the instrumental value that nature has for current and future human beings [1,72]. In a hypothetical situation in which you are the last human being on earth and have the capacity to destroy the earth, are you morally allowed to do so (since there will be no future human beings)? The argument aims to show that we would intuitively judge that it would be wrong to destroy nature. However, since there is no anthropocentric reason not to destroy nature, anthropocentrism must be false (one anonymous reviewer has criticized that my formulation of the charge against anthropocentrism is misleading. He argued the phrasing "[if] there is no anthropocentric reason not to destroy nature, [then] anthropocentrism must be false" can be simplified (dropping the double negation) to "[if] there is an anthropocentric reason to destroy nature, [then] anthropocentrism must be false". According to the reviewer, this re-formulation would make it evident that it is not likely that such a reason (to destroy nature) could easily be found, which in turn would take away the "questionable research program 'to show that there is not something'". I disagree for the following reason. The negative formulation is part of the whole gist of the argument: the aim is to show that a certain position cannot offer a reason to refrain from doing an (allegedly) immoral action. (The assumption of the argument is, that only the non-anthropocentrism gives you a reason to refrain from this action.) There is a difference between "belief system B does not give you a reason to refrain from doing $\mathrm{y}^{\text {" }}$ and "belief system $\mathrm{B}$ gives you a reason to do $\left.y^{\prime \prime}\right)$. The last person argument has been challenged and defended until very recently: there seems not to be a consensus on the matter as of yet [73-75]. I see merit in the last person argument, but a detailed analysis would go beyond the scope of this paper. 
If we look at these developments, we can see a pattern emerging in different philosophical traditions. Phenomenology, critical theory and some strands within analytic philosophy try in different ways to go beyond the paradigm of the individual as the center-stage of ethical and metaphysical theories. Heidegger points out the dependencies of the "Dasein" (the individual) from being in general; Jonas illustrate this relation of dependency in a careful analysis of the biological conditions of humans as organisms. These traditions thus mainly turn to 'nature'. Similarly, a turn to nature dominates early environmental ethics [76], both in the continental and in the analytic tradition. Critical theory shares the negative aspect with these two strands: a criticism of the over-emphasis on "isolated subjects". However, the alternative paradigm is not nature, but the focus is on the role of society. Critical theory and later theories of intersubjectivity [77] can be seen as an attempt to move beyond the rational utility maximizer paradigm and (re-)introduces the value of intersubjectivity. It is particularly the turn towards nature, however, that seems to open up new perspectives for a broader ethical foundation of the sustainable developmental goals. This re-evaluation of nature could be combined with philosophical and religious traditions from other cultures that put an equal emphasis on nature. Such a move beyond anthropocentrism could therefore either be supported by way of including elements from other cultures or by further developing recent criticism of anthropocentrism that has emerged in the West itself.

\section{Conclusions}

The Agenda 2030 makes frequent references to the human rights framework. The human rights framework is a powerful tool to protect the basic needs of the individual, but it can be challenged on two grounds. The human rights framework developed in close connection to contractualist ideas, from original theories of the social contract to modern contractualist interpretations of these ideas. I have tried to show that these approaches have their limits, when applied to sustainable developmental goals.

Firstly, it should be pointed out that, as a procedural theory, contracturalist individualism falls short in that future generations cannot enter the present social contract. They are thus systematically excluded from both the market place and the sphere of political power. Therefore, we need to strengthen the representation of future generation in our decision-making procedures. Secondly, contractualism assumes that individuals are primarily to be understood as utility-maximizers. This assumption is problematic, as it seems to be neither supported by psychological research nor plausible as a theory of grounding ethical commitments, such as the one that contracts should be kept. Therefore, it seems more reasonable to take ideal counter-factual consent under a veil of ignorance as starting point for contractualist individualism. However, even in this interpretation the starting point is still the (anticipation of the egoistic) preference of these hypothetical individuals.

A more fundamental critique is thus that the human rights framework can only account for an instrumental value of nature and is rooted in a specific type of Western individualism. I have therefore pointed to recent tendencies in otherwise very different philosophical traditions to re-evaluate the moral value of nature. It is striking to see, in different traditions such as phenomenology, critical theory and analytic environmental ethics, a growing skepticism within Western philosophy with regard to the sole reliance on individualism. Certainly, Western individualism has made contributions of utmost importance to our civilization: the discovery of human rights and the ideal of fundamental equality of all human beings are amongst those ideas of the West that we should not give up. However, whereas the West has put emphasis on the individual in ethical theory, other categories are less developed that deserve merit in the moral universe. The role of community values and the role of nature need to be considered more carefully in the underpinnings of an ethical framework for sustainable developmental goals.

There is work ahead to reconsider the potential of these alternative suggestions in the debate around sustainable developmental goals. The motivation to care for nature itself might give us the necessary resources to not only be the first generation that has a chance to end poverty, but to regard 
themselves as true stewards of the planet. We need to live up to this challenge, both for the sake of future generations and for the sake of nature itself.

Acknowledgments: The author likes to thank 4TU.Ethics (www.ethicsandtechnology.eu) for generously covering the costs for open access funding of this article.

Conflicts of Interest: The author declares no conflict of interest.

\section{References}

1. Sylvan, R. Is there a need for a new, an environmental, ethic? In Environmental Philosophy: From Animal Rights to Radical Ecology; Zimmerman, M.E., Callicott, J.B., Eds.; Prentice Hall: Upper Saddle River, NJ, USA, 1993.

2. Naess, A. The shallow and the deep, long-range ecology movement. A summary. Inquiry 1973, 16, 95-100. [CrossRef]

3. Jonas, H. The Imperative of Responsibility: In Search of an Ethics for the Technological Age; University of Chicago Press: Chicago, IL, USA, 1984; ISBN 978-0-226-40596-4.

4. Singer, P. Animal Liberation: Towards an End to Man's Inhumanity to Animals; Thornsons: Wellingborough, Northamptonshire, 1986; ISBN 978-0-7225-0845-9.

5. Regan, T. The Case for Animal Rights; University of California Press: Berkeley, CA, USA, 2004; ISBN 978-0-520-24386-6.

6. Hösle, V. Philosophie der ökologischen Krise: Moskauer Vorträge; Beck'sche Reihe, 432; Beck: München, Germany, 1994; ISBN 3406383688.

7. Eckersley, R. Liberal democracy and the rights of nature: The struggle for inclusion. Environ. Polit. 1995, 4, 169-198. [CrossRef]

8. Sovacool, B.K.; Burke, M.; Baker, L.; Kotikalapudi, C.K.; Wlokas, H. New frontiers and conceptual frameworks for energy justice. JEPO Energy Policy 2017, 105, 677-691. [CrossRef]

9. Sovacool, B.K.; Sovacool, B.K.; Dworkin, M.H. Energy justice: Conceptual insights and practical applications. Appl. Energy Appl. Energy 2015, 142, 435-444. [CrossRef]

10. UN General Assembly Transforming Our World: The 2030 Agenda for Sustainable Development. Available online: https://sustainabledevelopment.un.org/content/documents/21252030\%20Agenda\% 20for\%20Sustainable\%20Development\%20web.pdf (accessed on 21 December 2017).

11. Ishay, M. The History of Human Rights: From Ancient Times to the Globalization Era; University of California Press: Berkeley, CA, USA, 2009; ISBN 978-0-520-25641-5.

12. Freeman, M. Human Rights; Polity Press: Malden, MA, USA, 2017; ISBN 978-1-5095-1027-6.

13. Maine, H.S. Ancient Law; Thoemmes Press: Bristol, UK, 1996; ISBN 978-1-85506-483-6.

14. Lessnoff, M.H. Social Contract Theory; New York University Press: New York, NY, USA, 1990; ISBN 978-0-8147-5054-4.

15. Hösle, V. Morals and Politics; University of Notre Dame Press: Notre Dame, IN, USA, 2004; ISBN 978-0-268-03065-0.

16. Pogge, T. World Poverty and Human Rights: Cosmopolitan Responsibilities and Reforms; Polity: Cambridge, UK, 2012; ISBN 978-0-7456-4144-7.

17. Mario Bunge Ten Modes of Individualism—None of Which Works—And Their Alternatives. Philos. Soc. Sci. 2000, 30, 384-406.

18. Freeman, M. The Philosophical Foundations of Human Rights. Hum. Rights Q. 1994, 16, 491-514. [CrossRef]

19. Glendon, M.A. Foundations of Human Rights: The Unfinished Business. Am. J. Jurisprud. 1999, 44, 1-14. [CrossRef]

20. Donnelly, J. Universal Human Rights in Theory and Practice; Cornell University Press: Ithaca, NY, USA, 2013.

21. Cummiskey, D. Dignity, Contractualism and Consequentialism. Utilitas 2008, 20, 383-408. [CrossRef]

22. Rawls, J. A Theory of Justice; Belknap Press of Harvard University Press: Cambridge, MA, USA, 1971; ISBN 0-674-88010-2.

23. Kant, I. Toward Perpetual Peace and Other Writings on Politics, Peace, and History; Yale University Press: New Haven, CT, USA, 2008; ISBN 978-0-300-11794-3.

24. Bäckstrand, K. Democratizing Global Environmental Governance? Stakeholder Democracy after the World Summit on Sustainable Development. Eur. J. Int. Relat. 2006, 12, 467-498. [CrossRef] 
25. Bäckstrand, K. Multi-stakeholder partnerships for sustainable development: Rethinking legitimacy, accountability and effectiveness. Eur. Environ. 2006, 16, 290-306. [CrossRef]

26. Pols, A.; Spahn, A. Design for the Values of Democracy and Justice. In Handbook of Ethics, Values, and Technological Design; Dordrecht Holland: Boston, MA, USA, 2014; pp. 1-24.

27. Information for integrated Decision-Making \& Participation: Sustainable Development Knowledge Platform. Available online: https:/ / sustainabledevelopment.un.org/topics/information-integrated-decision-makingand-participation (accessed on 30 March 2018).

28. Shelton, D.L. Human Rights and the Environment: Substantive Rights; Social Science Research Network: Rochester, NY, USA, 2011.

29. Düwell, M. Human Dignity and Human Rights. In Humiliation, Degradation, Dehumanization; Library of Ethics and Applied Philosophy; Springer: Dordrecht, The Netherlands, 2011; pp. 215-230. ISBN 978-90-481-9660-9.

30. The Human Right to a Healthy Environment. Available online: https://www.cambridge.org/core/books / human-right-to-a-healthy-environment/4C9CA4D9C85E738DA524EFAC5D37D3A5 (accessed on 30 March 2018).

31. Alston, P. Ships Passing in the Night: The Current State of the Human Rights and Development Debate seen through the Lens of the Millennium Development Goals. Hum. Rights Q. 2005, 27, 755-829. [CrossRef]

32. Woods, K. Human Rights and Environmental Sustainability; E. Elgar: Cheltenham, UK, 2010; ISBN 978-1-84844-853-7.

33. Agyeman, J.; Bullard, R.D.; Evans, B. Exploring the Nexus: Bringing Together Sustainability, Environmental Justice and Equity. Space Polity 2002, 6, 77-90. [CrossRef]

34. Hamm, B.I. A Human Rights Approach to Development. Hum. Rights Q. 2001, 23, 1005-1031. [CrossRef]

35. Pols, A.; Spahn, A. Biofuels: Ethical Aspects. In Encyclopedia of Food and Agricultural Ethics; Thompson, P.B., Kaplan, D.M., Eds.; Springer: Dordrecht, The Netherlands, 2014; pp. 1-8. ISBN 978-94-007-6167-4.

36. Mutua, M. Savages, Victims, and Saviors: The Metaphor of Human Rights; Social Science Research Network: Rochester, NY, USA, 2001.

37. Schwartz, S.H. Individualism-Collectivism: Critique and Proposed Refinements. J. Cross-Cult. Psychol. 1990, 21, 139-157. [CrossRef]

38. Ignatieff, M. The Attack on Human Rights. Foreign Aff. 2001, 80, 102-116. [CrossRef]

39. Triandis, H.C. Individualism \& Collectivism; Westview Press: Boulder, CO, USA, 1995; ISBN 978-0-8133-1849-3.

40. Bielefeldt, H. "Western" Versus "Islamic" Human Rights Conceptions?: A Critique of Cultural Essentialism in the Discussion on Human Rights. Polit. Theory 2000, 28, 90-121. [CrossRef]

41. Shue, H. Basic Rights: Subsistence, Affluence, and U.S. Foreign Policy; Princeton Univercity Press: Princeton, NJ, USA, 1996; ISBN 978-0-691-02929-0.

42. Diener, E. Subjective well-being: The science of happiness and a proposal for a national index. Am. Psychol. 2000, 55, 34-43. [CrossRef] [PubMed]

43. Care, N.S. Decent People; Rowman \& Littlefield Publishers: Lanham, MD, USA, 2000; ISBN 0-7425-0708-4.

44. MacIntyre, A.C. After Virtue: A Study in Moral Theory; Bloomsbury: London, UK, 2014; ISBN 978-1-78093-625-3.

45. Heidegger, M. The Question Concerning Technology, and Other Essays, 1st ed.; Harper \& Row: New York, NY, USA, 1977; ISBN 978-0-06-131969-3.

46. Habermas, J. Justification and Application: Remarks on Discourse Ethics; MIT Press: Cambridge, MA, USA, 1993; ISBN 0-262-08217-9.

47. Smith, A.; Cannan, E. Wealth of Nations: An Inquiry into the Nature and Causes of the Wealth of Nations; Modern Library: New York, NY, USA, 1937.

48. Bell, D. Does anthropogenic climate change violate human rights? Crit. Rev. Int. Soc. Polit. Philos. 2011, 14, 99-124. [CrossRef]

49. Beyleveld, D.; Düwell, M.; Spahn, A. Why and How Should We Represent Future Generations in Policymaking? Jurisprudence 2015, 6, 549-566. [CrossRef]

50. Düwell, M. Human Dignity and Future Generations. In Cambridge Handbook on Human Dignity; Cambridge University Press: Cambridge, UK, 2014; pp. 551-558.

51. Van den Hove, S. Between consensus and compromise: Acknowledging the negotiation dimension in participatory approaches. Land Use Policy 2006, 23, 10-17. [CrossRef]

52. Apel, K.-O. Transformation der Philosophie; Suhrkamp: Frankfurt, Germany, 1973; ISBN 978-3-518-07353-7. 
53. Binmore, K.G. Game Theory and Social Contract; MIT Press: Cambridge, MA, USA, 1998; ISBN 978-0-262-02363-4.

54. Hardin, G. The Tragedy of the Commons. Science 1968, 162, 1243-1248. [CrossRef] [PubMed]

55. Gardiner, S.M. The Real Tragedy of the Commons. Philos. Public Aff. 2001, 30, 387-416. [CrossRef] [PubMed]

56. Axelrod, R. The Evolution of Cooperation; Basic Books: New York, NY, USA, 1984; ISBN 978-0-465-02122-2.

57. Otto, S.; Kaiser, F.G.; Arnold, O. The Critical Challenge of Climate Change for Psychology. Preventing Rebound and Promoting more Individual Irrationality. Eur. Psychol. 2014, 19, 96-106. [CrossRef]

58. Sally, D. Conversation and Cooperation in Social Dilemmas: A Meta-Analysis of Experiments from 1958 to 1992. Ration. Soc. 1995, 7, 58-92. [CrossRef]

59. Morris, M.W.; Sim, D.L.H.; Girotto, V. Distinguishing Sources of Cooperation in the One-Round Prisoner's Dilemma: Evidence for Cooperative Decisions Based on the Illusion of Control. J. Exp. Soc. Psychol. 1998, 34, 494-512. [CrossRef]

60. De Groot, J.I.M.; Steg, L. Value Orientations to Explain Beliefs Related to Environmental Significant Behavior: How to Measure Egoistic, Altruistic, and Biospheric Value Orientations. Environ. Behav. 2008, 40, 330-354. [CrossRef]

61. Steg, L.; Vlek, C. Encouraging pro-environmental behaviour: An integrative review and research agenda. J. Environ. Psychol. 2009, 29, 309-317. [CrossRef]

62. Values as predictors of environmental attitudes: Evidence for consistency across 14 countries. J. Environ. Psychol. 1999, 19, 255-265.

63. Mokyr, J. Institutions and the Origins of the Great Enrichment. Atl Econ. J. 2016, 44, 243-259. [CrossRef]

64. Sovacool, B.K. Energy E Ethics: Justice and the Global Energy Challenge; Palgrave Macmillan: Basingstoke, UK, 2013; ISBN 978-1-137-29865-2.

65. Sovacool, B.K.; Dworkin, M.H. Global Energy Justice: Problems, Principles, and Practices; Cambridge University Press: Cambridge, UK, 2014; ISBN 978-1-107-66508-8.

66. Husserl, E. Phenomenology and the Crisis of Philosophy; Harper \& Row: New York, NY, USA, 1994.

67. Jonas, H. The Phenomenon of Life: Toward a Philosophical Biology; Northwestern University Press: Evanston, IL, USA, 2001.

68. Vetlesen, A.J. The Denial of Nature: Environmental Philosophy in the Era of Global Capitalism; Routledge: Abingdon, UK, 2016; ISBN 978-0-415-72474-6.

69. Ballet, J.; Bazin, D. Hans Jonas: Bridging the Gap between Environmental Justice and Environmental Ethics. Available online: https://www.pdcnet.org/pdc/bvdb.nsf/purchase?openform\&fp=enviroethics\& id=enviroethics_2017_0039_0002_0175_0191 (accessed on 14 February 2018).

70. Habermas, J. Knowledge and Human Interests; Beacon Press: Boston, MA, USA, 1971; ISBN 978-0-8070-1540-7.

71. Habermas, J. Theory of Communicative Action: Lifeworld and System: A Critique of Functionalist Reason; Beacon Press: Boston, MA, USA, 1987; ISBN 0-8070-1400-1.

72. Attfield, R. The good of trees. In People, Penguins, and Plastic Trees: Basic Issues in Environmental Ethics; VanDeVeer, D., Pierce, C., Eds.; Wadsworth Publishing Company: Belmont, CA, USA, 1995.

73. Lee, K. Awe and Humility: Intrinsic Value in Nature. Beyond an Earthbound Environmental Ethics. R. Inst. Philos. Suppl. 1994, 36, 89-101. [CrossRef]

74. Peterson, M.; Sandin, P. The Last Man Argument Revisited. J. Value Inq. 2013, 47, 121-133. [CrossRef]

75. Weber, Z. Intrinsic Value and the Last Last Man. Ratio Ratio 2017, 30, 165-180. [CrossRef]

76. Hourdequin, M. Environmental Ethics; Bloomsbury Publishing: London, UK, 2015; ISBN 978-1-4725-0783-9.

77. Hösle, V. Die Krise der Gegenwart und die Verantwortung der Philosophie: Transzendentalpragmatik, Letztbegründung, Ethik; C.H. Beck: München, Germany, 1997; ISBN 978-3-406-39274-0.

(c) 2018 by the author. Licensee MDPI, Basel, Switzerland. This article is an open access article distributed under the terms and conditions of the Creative Commons Attribution (CC BY) license (http:/ / creativecommons.org/licenses/by/4.0/). 